\title{
Opioid-induced constipation: rationale for the role of norbuprenorphine in buprenorphine- treated individuals
}

\section{Lynn R Webster' \\ Michael Camilleri² \\ Andrew Finn ${ }^{3}$}

'PRA Health Sciences, Salt Lake City, UT, ${ }^{2}$ Mayo Clinic Rochester, MN, ${ }^{3}$ BioDelivery Sciences, Inc., Raleigh, NC, USA

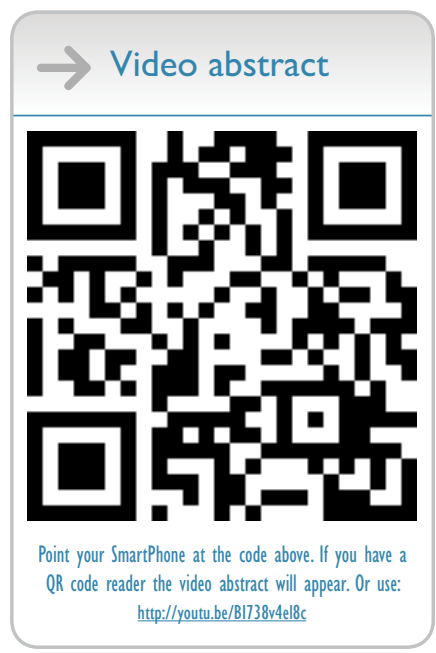

Correspondence: Lynn R Webster PRA Health Sciences, 3838 South 700 East \#202, Salt Lake City, UT, 84I06, USA $\mathrm{Tel}+\mathrm{I} 8012698200$

Email LRWebsterMD@gmail.com
This article was published in the following Dove Press journal:

Substance Abuse and Rehabilitation

14 June 2016

Number of times this article has been viewed
Abstract: Buprenorphine and buprenorphine-naloxone fixed combinations are effective for managing patients with opioid dependence, but constipation is one of the most common side effects. Evidence indicates that the rate of constipation is lower when patients are switched from sublingual buprenorphine-naloxone tablets or films to a bilayered bioerodible mucoadhesive buccal film formulation, and while the bilayered buccal film promotes unidirectional drug flow across the buccal mucosa, the mechanism for the reduced constipation is unclear. Pharmacokinetic simulations indicate that chronic dosing of sublingually administered buprenorphine may expose patients to higher concentrations of norbuprenorphine than buprenorphine, while chronic dosing of the buccal formulation results in higher buprenorphine concentrations than norbuprenorphine. Because norbuprenorphine is a potent full agonist at mu-opioid receptors, the differences in norbuprenorphine exposure may explain the observed differences in treatmentemergent constipation between the sublingual formulation and the buccal film formulation of buprenorphine-naloxone. To facilitate the understanding and management of opioid-dependent patients at risk of developing opioid-induced constipation, the clinical profiles of these formulations of buprenorphine and buprenorphine-naloxone are summarized, and the incidence of treatment-emergent constipation in clinical trials is reviewed. These data are used to propose a potential role for exposure to norbuprenorphine, an active metabolite of buprenorphine, in the pathophysiology of opioid-induced constipation.

Keywords: opioid, safety, buccal, sublingual, dependence, maintenance

\section{Introduction}

Maintenance treatment of opioid-dependent patients typically involves a combination of psychosocial approaches (eg, counseling, prevention education, and recovery support services) and office-based pharmacological substitution therapy with an oral transmucosal agent. Options include buprenorphine or fixed combinations of buprenorphine and naloxone (BN) that are supplied in three formulations: sublingual tablets or single-layered sublingual films for sublingual or buccal use (sublingual buprenorphine-naloxone [SLBN], Suboxone ${ }^{\circledR}$ Indivior Inc., Richmond, VA, USA) and bilayered bioerodible mucoadhesive buccal films (buccal buprenorphine-naloxone $[\mathrm{BBN}]$, Bunavail, ${ }^{\circledR}$ BioDelivery Sciences International, Inc., Raleigh, NC, USA). ${ }^{1,2}$ These BN agents have been shown to improve outcomes in opioid-dependent patients, ${ }^{3-5}$ and while they are generally safe and well tolerated, with predictable side-effect profiles, as with all opioids, constipation is among the most common side effects. ${ }^{5}$

The mechanisms of opioid-induced constipation (OIC) are complex, involving mu-opioid-mediated effects on the enteric nervous system that result in decreased 
intestinal fluid secretion and increased fluid absorption, as well as decreased muscle contraction and motility of the small intestine and colon, resulting in increased colonic transit time..$^{6-8}$ Endogenous opioids, including endorphins, enkephalins, and dynorphins, have been shown to reduce acetylcholine-mediated intestinal motor and secretory activities. ${ }^{9-11}$ Experimental data also indicate that mu-opioid receptors in the brain may also significantly delay intestinal transit. ${ }^{12,13}$ Local effects on mu-opioid receptors in the intestine may also impact intestinal functions. Thus, the intraluminal administration of opioid receptor antagonists (eg, naloxone, $N$-methylnaloxone), which are undetectable in the general circulation due to insufficient absorption from the intestinal lumen, may prevent intravascular morphine from depressing motility. ${ }^{14}$ These effects, together with the increased resting anal sphincter tone and decreased reflex relaxation of the anal sphincter produced by exogenous opioids, ${ }^{15}$ result in symptoms of OIC.

The significant clinical consequence of the development of OIC is such that patients may reduce or stop their opioid medication to achieve a positive impact on their quality of life, ${ }^{3,11,16,17}$ and OIC is one of the most common reasons patients avoid or abandon therapeutic opioid use. ${ }^{18,19}$ Although clinical experience suggests that most opioiddependent patients experience mild or moderate symptoms that can be managed with over-the-counter laxatives, the potentially serious impact on quality of life, secondary symptoms, and complications of unmanaged constipation underscore its clinical importance (Table 1). ${ }^{17,20,21}$

\section{Methods}

To facilitate the understanding of OIC and management of opioid-dependent patients at risk of developing OIC with the goal of preventing the problem, this paper briefly summarizes the clinical profiles of SLBN and BBN and reviews published evidence of the incidence of treatment-emergent constipation associated with these therapies. Separate searches were performed on PubMed for "sublingual buprenorphine naloxone" and "buccal buprenorphine naloxone", with the filters set to include only clinical trials. Of the records related

Table I Secondary symptoms and complications of unmanaged constipation

\begin{tabular}{ll}
\hline Incomplete evacuation & Hemorrhoids \\
Abdominal distension & Rectal pain and burning \\
Bloating & Fecal impaction \\
Anorexia & Bowel obstruction or rupture \\
Nausea/vomiting & Interference with drug administration \\
& and absorption \\
\hline
\end{tabular}

Note: Data from studies..$^{17,20,21}$ to $\operatorname{SLBN}(\mathrm{N}=36)$ or $\mathrm{BBN}(\mathrm{N}=3)$, only one clinical study with each formulation reported constipation rates.

\section{Buprenorphine}

Initially developed for the treatment of pain, buprenorphine is a semisynthetic partial agonist at mu-opioid receptor and an antagonist at kappa opioid receptor sites. ${ }^{22,23}$ Buprenorphine is widely used to treat opioid-dependent patients because the reward effects are milder than those of full mu-opioid agonists $^{24}$, its binding to mu-opioid receptors is not easily displaced by other opioids, and it has a lower risk of abuse and dose-limited effects on respiratory depression. ${ }^{25,26}$ Oral dosing of buprenorphine is not feasible due to extensive first-pass liver metabolism, which markedly limits its bioavailability. In contrast, oral transmucosal administration is associated with bioavailability up to $50 \%{ }^{27}$

Buprenorphine has been demonstrated to be safe and effective for use in induction, stabilization, and long-term maintenance of opioid-dependent patients, as measured by reduced consumption of illicit opioids. ${ }^{28} \mathrm{~A}$ recent Cochrane review found it to be an effective medication in the maintenance treatment of heroin dependence, retaining people in treatment at any sublingual dose $>2 \mathrm{mg}$ and suppressing illicit opioid use when administered at sublingual doses $\geq 16$ mg. ${ }^{28}$ Compared with methadone, buprenorphine substitution treatment has been shown to decrease hospital admissions, morbidity, and mortality, ${ }^{3,4}$ with potentially less sedation. ${ }^{29}$ It has a lower abuse potential, carries less stigma, and allows for greater flexibility in treatment than methadone..$^{30}$ In the gastrointestinal (GI) tract, buprenorphine inhibits acetylcholine-induced ileal muscle contraction, and subcutaneous injections in mice at doses ranging from 1.0 to $20.0 \mathrm{mg} / \mathrm{kg}$ can slow GI transit by $<50 \%$. ${ }^{31}$ About $8 \%$

Table 2 Gastrointestinal adverse events (\%) after 4 weeks of treatment with the sublingual tablet formulations of buprenorphinenaloxone (16/4 mg) or buprenorphine (16 mg)

\begin{tabular}{lllll}
\hline Event & \multicolumn{2}{l}{ Treatment (\%) } & P-value $^{\mathbf{a}}$ \\
\cline { 2 - 4 } & $\begin{array}{l}\text { Buprenorphine } \\
(\mathbf{n = 1 0 3 )}\end{array}$ & $\begin{array}{l}\text { SLBN } \\
(\mathbf{n}=107)\end{array}$ & $\begin{array}{l}\text { Placebo } \\
(\mathbf{n}=107)\end{array}$ & \\
\hline Nausea & 14 & 15 & $1 \mathrm{I}$ & 0.73 \\
Constipation & 8 & 12 & 3 & 0.03 \\
Abdominal pain & 12 & $\mathrm{II}$ & 7 & 0.37 \\
Vomiting & 8 & 8 & 5 & 0.66 \\
Diarrhea & 5 & 4 & 15 & 0.005 \\
\hline
\end{tabular}

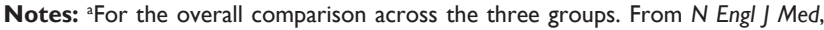
Fudala P], Bridge TP, Herbert S, et al; Buprenorphine/Naloxone Collaborative Study Group, Office-based treatment of opiate addiction with a sublingual tablet formulation of buprenorphine and naloxone, 349, 949-958. ${ }^{5}$ Copyright (๔) 2003 Massachusetts Medical Society. Reprinted with permission from Massachusetts Medical Society.

Abbreviation: SLBN, buprenorphine-naloxone sublingual tablet. 
of subjects receiving buprenorphine reported an adverse event of constipation after 4 weeks of sublingual treatment with the medication, significantly more than placebo $(\sim 3 \%$, $P=0.03$, Table 2). ${ }^{5}$

\section{Buprenorphine combination products Sublingual buprenorphine-naloxone tablets}

SLBN has been approved for the office-based management of patients with opioid dependence since $2002 .{ }^{32}$ Its efficacy and safety in opioid-dependent patients have been documented in published studies. ${ }^{5,26,30,33}$ In a controlled clinical trial, it has significantly outperformed placebo for proportion of urine samples that were negative for opiates and the proportion of subjects with opiate craving $(P<0.001$ for both comparisons). ${ }^{5}$ Despite an overall rate of adverse events that was roughly similar to placebo, as shown in Table 2, the incidence of constipation in SLBN-treated subjects was four times greater than placebo-treated subjects $(P=0.03) .^{5}$

\section{Buccal buprenorphine-naloxone films}

$\mathrm{BBN}$ is a novel transmucosal buprenorphine-naloxone combination product formulated as a small, thin, bilayered dissolvable film that adheres to the buccal mucosa and provides approximately twice the bioavailability of buprenorphine compared with SLBN tablets containing double the buprenorphine dose. ${ }^{2,34}$ Mechanistically, BBN can be distinguished from buccally administered SLBN by the presence of a backing layer, which promotes unidirectional flow across the buccal mucosa; SLBN for buccal administration is a single-layer

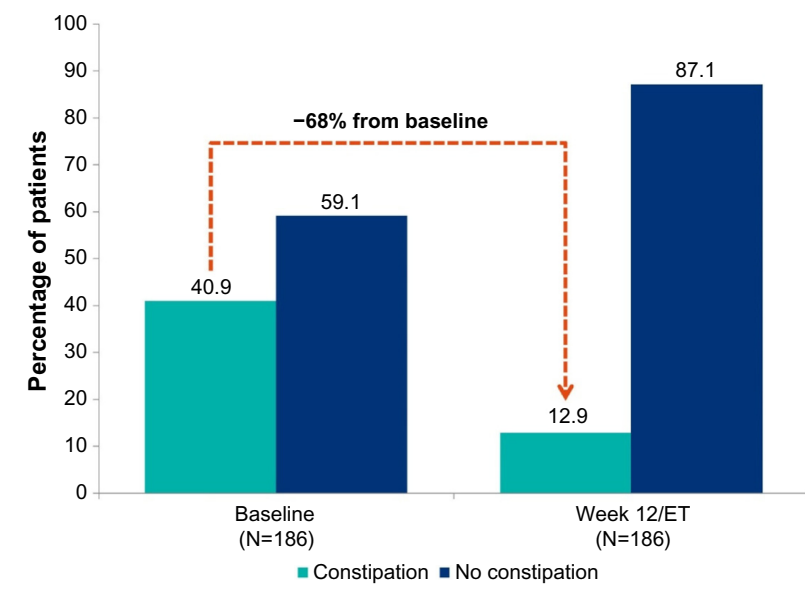

Figure I Constipation* at baseline and at week 12 in patients converted from SLBN to $B B N(\mathrm{~N}=186)$.

Notes: *As reported on a BN-related symptom checklist; $95 \%$ confidence intervals on $68 \%$ risk reduction are $60 \%-77 \%$. Reprinted from Clin Ther, 37 , Sullivan JG, Webster L, Novel buccal film formulation of buprenorphine-naloxone for the maintenance treatment of opioid dependence: a 12-week conversion study, 1064-1075,,$^{34}$ Copyright (C) 2015, with permission from Elsevier.

Abbreviations: BBN, buccal buprenorphine-naloxone film; ET, early termination; SLBN, sublingual buprenorphine-naloxone tablets or films. film without a backing layer. ${ }^{1,2}$ In an open-label study in 249 adult opioid-dependent subjects stabilized on SLBN tablets or film at a dose of $16 \mathrm{mg} /$ day and switched to a mean dose of $8 \mathrm{mg}$ BBN for 12 weeks, $92 \%$ of subjects had urine samples that were negative for nonprescribed opioids. As shown in Figure 1, of the 186 subjects who completed a checklist of common side effects (asking for presence or absence) of BN at baseline and day $84,41 \%(76 / 186)$ reported constipation at the time of SLBN discontinuation, and before treatment with $\mathrm{BBN}$, and 13\% (24/186) reported constipation after 12 weeks of BBN treatment, a risk reduction of $68 \%(52 / 76$; 95\% confidence intervals 60\%-77\%). ${ }^{34}$ Approximately 3\% (7/249) of subjects on BBN reported treatment-emergent constipation over the course of the 12-week study. ${ }^{34}$

The 2:1 buprenorphine dose conversion ratio from the mean baseline SLBN dose to the mean BBN dose at the end of the study aligns with results from a bioequivalence study in healthy volunteers. In that single-dose, crossover pharmacokinetic study, which compared the rate and extent of BN exposure from 4.2/0.7 mg BBN with 8/2 mg SLBN tablets in 80 healthy adults who had been given naltrexone, buprenorphine exposure from BBN was bioequivalent with SLBN (90\% confidence intervals for maximum plasma concentration $\left[\mathrm{C}_{\max }\right]$, area under the plasma concentration-time curve from time 0 to the last measurable concentration $\left[\mathrm{AUC}_{\text {last }}\right.$, and $\mathrm{AUC}$ extrapolated to infinity $\left[\mathrm{AUC}_{\mathrm{inf}}\right]$ ranged from $88 \%$ to $118 \%$ ), while exposure to naloxone and norbuprenorphine were, respectively, 33\% and $40 \%$ less than with SLBN (Table 3). ${ }^{35}$

Based on the single-dose data from the study comparing SLBN (8 mg) with BBN (4.2 mg) in healthy subjects, plasma buprenorphine and norbuprenorphine concentration exposures $\left(\mathrm{AUC}_{0-24}\right)$ were modeled for steady-state conditions during daily dosing with SLBN $16 \mathrm{mg}$ or BBN $8 \mathrm{mg}$. As shown in Table 4, projected norbuprenorphine exposure with SLBN was nearly double that of BBN, while the projected $\mathrm{AUC}_{0-24}$ exposures for buprenorphine were roughly equivalent with both formulations. Importantly, the projected steady-state plasma norbuprenorphine concentrations with SLBN exceeded the steady-state buprenorphine concentrations by $\sim 30 \%$, whereas projected plasma norbuprenorphine concentrations with $\mathrm{BBN}$ were nearly 30\% lower than buprenorphine. The difference is presumed to be due to higher transmucosal bioavailability and lower amounts of buprenorphine exposed to first-pass liver metabolism.

\section{Potential role of norbuprenorphine in constipation}

It is unclear why the rates of constipation decreased in subjects switched from SLBN to BBN. While subcutaneous 
Table 3 Systemic exposure of 4.2/0.7 mg BBN film and 8/2 mg SLBN tablet $(\mathrm{N}=80)$

\begin{tabular}{|c|c|c|c|c|c|}
\hline \multirow[t]{2}{*}{ PK parameter } & \multicolumn{2}{|l|}{ Geometric mean } & \multirow{2}{*}{$\begin{array}{l}\text { Geometric mean } \\
\text { ratio (\%) } \\
\text { BBN/SLBN }\end{array}$} & \multicolumn{2}{|c|}{$\begin{array}{l}90 \% \mathrm{Cl} \text { of the geometric } \\
\text { ratio }\end{array}$} \\
\hline & BBN 4.2/0.7 mg & SLBN $8 / 2 \mathrm{mg}$ & & Lower & Upper \\
\hline \multicolumn{6}{|l|}{ Buprenorphine } \\
\hline $\ln \left(C_{\max }\right)$ & 3.15 & 2.89 & 109.07 & 100.49 & 118.39 \\
\hline $\ln \left(A \cup C_{\text {last }}\right)$ & 24.21 & 25.40 & 95.35 & 88.92 & 102.24 \\
\hline $\ln \left(A \cup C_{\text {inf }}\right)$ & 25.57 & 27.03 & 94.62 & 88.48 & 101.19 \\
\hline \multicolumn{6}{|c|}{ Norbuprenorphine } \\
\hline $\ln \left(C_{\max }\right)$ & 0.46 & 1.16 & 39.54 & 36.35 & 43.02 \\
\hline $\ln \left(A \cup C_{\text {last }}\right)$ & 16.18 & 33.70 & 48.00 & 43.86 & 52.52 \\
\hline $\ln \left(A \cup C_{i n f}\right)$ & 18.81 & 36.41 & 51.64 & 48.20 & 55.33 \\
\hline \multicolumn{6}{|l|}{ Naloxone } \\
\hline $\ln \left(C_{\max }\right)$ & 117.57 & 161.37 & 72.86 & 65.94 & 80.51 \\
\hline $\ln \left(A \cup C_{\text {last }}\right)$ & 298.14 & 442.28 & 67.41 & 61.98 & 73.31 \\
\hline $\ln \left(A \cup C_{\text {inf }}\right)$ & 304.39 & 458.95 & 66.32 & 61.14 & 71.94 \\
\hline
\end{tabular}

Note: Data from Vasisht et al. ${ }^{35}$

Abbreviations: BBN, buccal buprenorphine-naloxone film; Cl, confidence interval; SLBN, sublingual buprenorphine-naloxone tablets or films; PK, pharmacokinetic; $\mathrm{C}_{\text {max' }}$ maximum plasma concentration; $A \cup C$, area under the plasma concentration-time curve; $A \cup C_{\text {last }}$ AUC from time 0 to the last measurable concentration; $A \cup C_{\text {inf }} A \cup C$ extrapolated to infinity.

naloxone ( $0.8 \mathrm{mg}$ every 6 hours) has been found to accelerate transit in the colon of healthy human volunteers, ${ }^{36}$ and evidence suggests it can reverse idiopathic chronic constipation, benefit patients with intestinal pseudo-obstruction and constipation-predominant irritable bowel syndrome, ${ }^{37}$ and improve the symptoms of $\mathrm{OIC}^{38,39}$ when given at high doses orally (eg, $10 \mathrm{mg}$ bid in the constipation-predominant irritable bowel syndrome trial), it seems unlikely to have played a role in the different outcomes with respect to constipation in the study of opioid-dependent subjects stabilized on SLBN and switched to BBN. Not only do both study drugs contain naloxone, but also the rate and extent of naloxone exposure with BBN was one-third lower than with SLBN. Moreover, another orally administered, poorly bioavailable mu-opioid antagonist, naltrexone $(50 \mathrm{mg})$ or subcutaneous methylnaltrexone $(0.3 \mathrm{mg} / \mathrm{kg})$, did not accelerate colonic transit in healthy volunteers. ${ }^{40,41} \mathrm{All}$ of these data argue against a role for the naloxone in BBN as the reason for improved bowel function.

Rather, the steady-state plasma concentration projections observed in this study suggest that the lower incidence of constipation with BBN relative to SLBN may be due to reduced exposure of enteric mu-receptors to norbuprenorphine. In randomized studies in opioid-dependent subjects, mean steady-state plasma concentrations of this major peripherally active metabolite of buprenorphine have matched or surpassed the parent compound following sublingual administration. ${ }^{42,43}$ These data are therefore consistent with the hypothesis that, as a potent full agonist at mu-receptors, ${ }^{44}$ norbuprenorphine contributes to the overall peripheral pharmacological effects of buprenorphine in the regulation of multiple GI processes in vivo. Its lack of penetration of the blood-brain barrier into the central nervous system suggests little central nervous system contribution of norbuprenorphine to the GI processes. ${ }^{45}$

\section{Implications for clinical practice}

These data indicate that the lower rate of constipation observed with the BBN formulation may be the result of reduced exposure to norbuprenorphine. It therefore appears reasonable to query opioid-dependent patients who are at risk of or report OIC symptoms and possible effects on quality of life in order to enhance adherence to medication regimens. In addition, since there is no significant difference between SLBN tablets and single-layered films with regard to plasma levels of naloxone and norbuprenorphine, ${ }^{46}$ and

Table 4 Predicted buprenorphine and norbuprenorphine exposure with SLBN tablets and BBN films: daily dosing and steady-state conditions

\begin{tabular}{llllll}
\hline & \multicolumn{2}{l}{ Daily $\left(\right.$ AUC $\left._{0-24}\right) \mathbf{n g} \times \mathbf{h} / \mathbf{m L}$} & & \multicolumn{2}{l}{ Steady-state $($ AUC $) \mathbf{n g} \times \mathbf{h} / \mathbf{m L}$} \\
\cline { 2 - 3 } & Norbuprenorphine & Buprenorphine & & Norbuprenorphine & Buprenorphine \\
\hline BBN $(n=65)$ & 15 & 37.8 & 37.1 & 51.9 \\
SLBN $(n=68)$ & 29.6 & 40.8 & 71.3 & 54.3 \\
\hline
\end{tabular}

Abbreviations: AUC, area under the plasma concentration-time curve; BBN, buccal buprenorphine-naloxone film; SLBN, sublingual buprenorphine-naloxone tablet. 
treatment-emergent constipation rates with SLBN films across 19 pharmacokinetic studies in healthy volunteers $(11 \%)^{46}$ are similar to the clinical study with SLBN tablets $(12 \%),{ }^{5}$ if management of OIC is needed for patients who are being treated with SLBN, strategies to minimize exposure to norbuprenorphine may be considered. Evidence suggests that $\mathrm{BBN}$ provides adequate symptom control with respect to opioid dependence and is well tolerated, with low reported rates of constipation, good adherence, and favorable patient acceptance. $^{34}$

\section{Conclusion}

Buprenorphine is an effective intervention for the management of opioid dependence, but patients are at risk for a range of GI symptoms, including OIC. Pharmacokinetic simulations indicate that chronic dosing of sublingually administered agents may expose patients to higher concentrations of norbuprenorphine than buprenorphine due to swallowing of unabsorbed buprenorphine, whereas chronic dosing of the bilayered bioerodible mucoadhesive buccal formulation, which provides higher bioavailability and is efficiently absorbed across the buccal mucosa, results in higher buprenorphine concentrations than norbuprenorphine. These data support the hypothesis that exposure to norbuprenorphine, an active metabolite of buprenorphine, plays a role in the pathophysiology of OIC and that differences in norbuprenorphine exposure may explain the observed differences in constipation between SLBN and BBN.

\section{Acknowledgments}

The authors wish to thank Sarah DeRossett and Susan Kerls for their assistance in preparing the manuscript. Medical writing services were provided by Christopher Caiazza.

\section{Disclosure}

MC is supported by NIH RO1 DK92179. BioDelivery Sciences, Inc., developer of bioerodible mucoadhesive buprenorphine-naloxone buccal film, has provided research support to LRW and MC. AF is a retired employee of BioDelivery Sciences, Inc. The authors report no other conflicts of interests in this work.

\section{References}

1. Suboxone [prescribing information]. Available from: http://www. suboxone.com/content/pdfs/SuboxonePI.pdf. Accessed November 17, 2015.

2. Bunavail [prescribing information]. Available from: http://www.bdsi.com/ siteres.aspx?resid=5a738443-a797-41cd-a39a-a8deb2a4a585. Accessed November 17, 2015.
3. Bell J, Trinh L, Butler B, Randall D, Rubin G. Comparing retention in treatment and mortality in people after initial entry to methadone and buprenorphine treatment. Addiction. 2009;104:1193-1200.

4. Jones ES, Moore BA, Sindelar JL, O'Connor PG, Schottenfeld RS, Fiellin DA. Cost analysis of clinic and office-based treatment of opioid dependence: results with methadone and buprenorphine in clinically stable patients. Drug Alcohol Depend. 2009;99:132-140.

5. Fudala PJ, Bridge TP, Herbert S, et al; Buprenorphine/Naloxone Collaborative Study Group. Office-based treatment of opiate addiction with a sublingual tablet formulation of buprenorphine and naloxone. $N$ Engl J Med. 2003;349:949-958.

6. Bagnol D, Mansour A, Akil H, Watson SJ. Cellular localization and distribution of the cloned mu and kappa opioid receptors in rat gastrointestinal tract. Neuroscience. 1997;81:579-591.

7. McKay JS, Linaker BD, Turnberg LA. Influence of opiates on ion transport across rabbit ileal mucosa. Gastroenterology. 1981;80: 279-284.

8. Fickel J, Bagnol D, Watson SJ, Akil H. Opioid receptor expression in the rat gastrointestinal tract: a quantitative study with comparison to the brain. Brain Res Mol Brain Res. 1997;46:1-8.

9. Rang HP, Dale MM, Ritter JM. Analgesic drugs. Pharmacology. 1999; 13:579-603.

10. Thomas J. Opioid-induced bowel dysfunction. J Pain Symptom Manage. 2008;35:103-113.

11. Yuan CS, Foss JF, O'Connor M, Moss J, Roizen MF. Gut motility and transit changes in patients receiving long-term methadone maintenance. J Clin Pharmacol. 1998;38:931-935.

12. Thörn SE, Wattwil M, Lindberg G, Säwe J. Systemic and central effects of morphine on gastroduodenal motility. Acta Anaesthesiol Scand. 1996;40:177-186.

13. Manara L, Bianchetti A. The central and peripheral influences of opioids on gastrointestinal propulsion. Annu Rev Pharmacol Toxicol. 1985;25:249-273.

14. Reber P, Brenneisen R, Flogerzi B, Batista C, Netzer P, Scheurer U. Effect of naloxone-3-glucuronide and N-methylnaloxone on the motility of the isolated rat colon after morphine. Dig Dis Sci. 2007;52:502-507.

15. Holzer P. Opioids and opioid receptors in the enteric nervous system: from a problem in opioid analgesia to a possible new prokinetic therapy in humans. Neurosci Lett. 2004;361:192-195.

16. Mancini I, Bruera E. Constipation in advanced cancer patients. Support Care Cancer. 1998;6:356-364.

17. Benyamin R, Trescot AM, Datta S, et al. Opioid complications and side effects. Pain Physician. 2008;11(2 Suppl):S105-S120.

18. Meissner W, Schmidt U, Hartmann M, Kath R, Reinhart K. Oral naloxone reverses opioid-associated constipation. Pain. 2000;84:105-109.

19. Thorpe DM. Management of opioid-induced constipation. Curr Pain Headache Rep. 2001;5:237-240.

20. Kurz A, Sessler DI. Opioid-induced bowel dysfunction: pathophysiology and potential new therapies. Drugs. 2003;63:649-671.

21. Holzer P. Treatment of opioid-induced gut dysfunction. Expert Opin Investig Drugs. 2007;16:181-194.

22. Mello NK, Mendelson J. Behavioral pharmacology of buprenorphine. Drug Alcohol Depend. 1985;14:283-303.

23. Pergolizzi J, Aloisi AM, Dahan A, et al. Current knowledge of buprenorphine and its unique pharmacological profile. Pain Pract. 2010;10:428-450.

24. Lutfy K, Cowan A. Buprenorphine: a unique drug with complex pharmacology. Curr Neuropharmacol. 2004;2:395-402.

25. Mello NK, Walsh S, Preston K, Stitzer M, Cone E, Bigelow G. Clinical pharmacology of buprenorphine: ceiling effects at high doses. Clin Pharmacol Ther. 1994;55:569-580.

26. Strain EC, Preston K, Liebson I, Bigelow G. Buprenorphine effects in methadone-maintained volunteers: effect at two hours after methadone. J Pharmacol Exp Ther. 1995;272:628-638.

27. Yokell MA, Zaller ND, Green TC, Rich JD. Buprenorphine and buprenorphine/naloxone diversion, misuse, and illicit use: an international review. Curr Drug Abuse Rev. 2011;4:28-41. 
28. Johnson RE, Jaffe JH, Fudala PJ. A controlled trial of buprenorphine treatment for opioid dependence. JAMA. 1992;267:2750-2755.

29. Mattick RP, Breen C, Kimber J, Davoli M. Buprenorphine maintenance versus placebo or methadone maintenance for opioid dependence. Cochrane Database Syst Rev. 2014;2:CD002207.

30. Mauger S, Fraser R, Gill K. Utilizing buprenorphine-naloxone to treat illicit and prescription-opioid dependence. Neuropsychiatr Dis Treat. 2014; 10:587-598.

31. Zhou PL, Li YL, Yan LD, et al. Effect of thienorphine on intestinal transit and isolated guinea-pig ileum contraction. World J Gastroenterol. 2013;19:1444-1450.

32. U.S. Food and Drug Administration. Suboxone Approval History. Available from: http://www.accessdata.fda.gov/drugsatfda_docs/ appletter/2002/20732,207331tr.pdf.

33. Finch JW, Kamien JB, Amass L. Two-year experience with buprenorphinenaloxone (Suboxone) for maintenance treatment of opioid dependence within a private practice setting. J Addict Med. 2007;1:104-110.

34. Sullivan JG, Webster L. Novel buccal film formulation of buprenorphine-naloxone for the maintenance treatment of opioid dependence: a 12-week conversion study. Clin Ther. 2015;37: 1064-1075.

35. Vasisht N, Stark J, Bai SA, Finn A. Buprenorphine/naloxone buccal film has a relative buprenorphine bioavailability approximately twice that of buprenorphine/naloxone sublingual tablet. In:2014 ASAM 45th Annual Medical-Scientific Conference, Poster \#10, April 10-13, 2014; Orlando, FL.

36. Kaufman PN, Krevsky B, Malmud LS, et al. Role of opiate receptors in the regulation of colonic transit. Gastroenterology. 1988;94: 1351-1356.

37. DeHaven-Hudkins DL, DeHaven RN, Little PJ, Techner LM. The involvement of the $\mu$-opioid receptor in gastrointestinal pathophysiology: therapeutic opportunities for antagonism at this receptor. Pharmacol Ther. 2008;117:162-187.

38. DePriest AZ, Miller K. Oxycodone/naloxone: role in chronic pain management, opioid-induced constipation, and abuse deterrence. Pain Ther. 2014;3:1-15.
39. Smith K, Hopp M, Mundin G, et al. Naloxone as part of a prolonged release oxycodone/naloxone combination reduces oxycodone-induced slowing of gastrointestinal transit in healthy volunteers. Expert Opin Investig Drugs. 2011;20:427-439.

40. Foxx-Orenstein AE, Camilleri M, Szarka LA, et al. Does coadministration of a non-selective opiate antagonist enhance acceleration of transit by a 5-HT4 agonist in constipation-predominant irritable bowel syndrome? A randomized controlled trial. Neurogastroenterol Motil. 2007;19:821-830.

41. Wong BS, Rao AS, Camilleri M, et al. The effects of methylnaltrexone alone and in combination with acutely administered codeine on gastrointestinal and colonic transit in health. Aliment Pharmacol Ther. 2010;32:884-893.

42. Kuhlman JJ Jr, Levine B, Johnson RE, Fudala PJ, Cone EJ. Relationship of plasma buprenorphine and norbuprenorphine to withdrawal symptoms during dose induction, maintenance and withdrawal from sublingual buprenorphine. Addiction. 1998;93:549-559.

43. Brown SM, Holtzman M, Kim T, Kharasch ED. Buprenorphine metabolites, buprenorphine-3-glucuronide and norbuprenorphine3-glucuronide, are biologically active. Anesthesiology. 2011;115: 1251-1260.

44. Yassen A, Kan J, Olofsen E, Suidgeest E, Dahan A, Danhof M. Pharmacokinetic-pharmacodynamic modeling of the respiratory depressant effect of norbuprenorphine in rats. J Pharmacol Exp Ther. 2007;321:598-607.

45. Huang P, Kehner GB, Cowan A, Liu-Chen LY. Comparison of pharmacological activities of buprenorphine and norbuprenorphine: norbuprenorphine is a potent opioid agonist. J Pharmacol Exp Ther. 2001;297:688-695.

46. Commonwealth of Australia. Australian Public Assessment Report for Buprenorphine/Naloxone. Available from: https://www.tga.gov.au/ auspar/auspar-buprenorphine-naloxone. Accessed March 9, 2016.
Substance Abuse and Rehabilitation

\section{Publish your work in this journal}

Substance Abuse and Rehabilitation is an international, peer-reviewed, open access journal publishing original research, case reports, editorials, reviews and commentaries on all areas of addiction and substance abuse and options for treatment and rehabilitation. The manuscript management system is completely online and includes a very quick and fair

\section{Dovepress}

peer-review system. Visit http://www.dovepress.com/testimonials.php to read real quotes from published authors. 